\title{
US health care. II: The cost problem
}

\author{
Jennifer Dixon
}

The third and final part in this series will appear in next week's issue. Part I appeared last week
Health Services Research Unit, London School of Hygiene and Tropical Medicine, London WC1E 7HT

Jennifer Dixon, honorary lecturer in public health medicine

BM7 1992;305:878-80
Last week we examined access to health care in the United States and how it has changed in recent years. This paper looks at the costs of American health care and the impact of important cost containment strategies.

Health care spending has risen faster in the United States than in any other member nation of the Organisation for Economic Cooperation and Development (see figure). During 1970 to 1990 the rise was almost $12 \%$ a year. ${ }^{1}$ In 1990 the United States spent a staggering $\$ 666 \cdot 2$ billion or $12 \cdot 4 \%$ of its gross domestic product on health care- $\$ 2566$ per head of population. ${ }^{2}$ Concern is mounting because costs are digging deeper into the pockets of those who foot the health care bill-mainly businesses, the government, and the public-all of which have been hard hit by the recession and current slow economic growth Meanwhile almost 36 million people have no health insurance at all, ${ }^{3}$ many going without even basic care. Most agree that any reform of health care in the United States must include serious cost containment measures if the "paradox of excess and deprivation" is to be addressed.

This article examines why the costs of health care have risen, their effects, and the efforts to contain costs in relation to four groups of Americans-those with no health insurance, those with government funded health insurance through Medicare (the health programme for the elderly) and through Medicaid (the health programme for the poor), and those with private health insurance.

\section{Why costs have risen}

For the past decade general inflation has been responsible for over half of the rise in health spending, while medical price inflation (excluding general inflation) and an increase in the volume and intensity of services used by patients have caused most of the rest. ${ }^{5}$ Population changes have had a much smaller effect.

Medical prices and use of services have spiralled because of the inherent system of incentives that exists in American health care. For most Americans money spent on health care goes through third party insurers, whether these are the government or private insurance companies. Since insurance insulates patients from the full costs of care patient demand is less constrained by worries about costs and providers of services are less sensitive about raising prices. Where hospitals and doctors are paid on a fee for service basis the incentive is to provide more services for more fees. The scope for this supplier induced demand is widened by the lack of information available on which services are clinically necessary and the oversupply of specialists ${ }^{6}$ with ready access to high technology services.

Because there are many payers of health care (including federal, state, and local governments; businesses; insurance companies; and the public) purchasing power is fragmented and the ability to curb price increases or the activity of powerful providers is weakened. The tax breaks offered by federal government have encouraged businesses to compensate workers with health benefits rather than wages, ${ }^{8}$ and more benefits have meant more demand and use of services. Finally, a health care system with multiple payers and providers has led to high administrative costs - estimated to be $22 \%$ of the total health expenditure in the United States. ${ }^{9}$ These factors add up to an explosive mix which has pushed costs up.

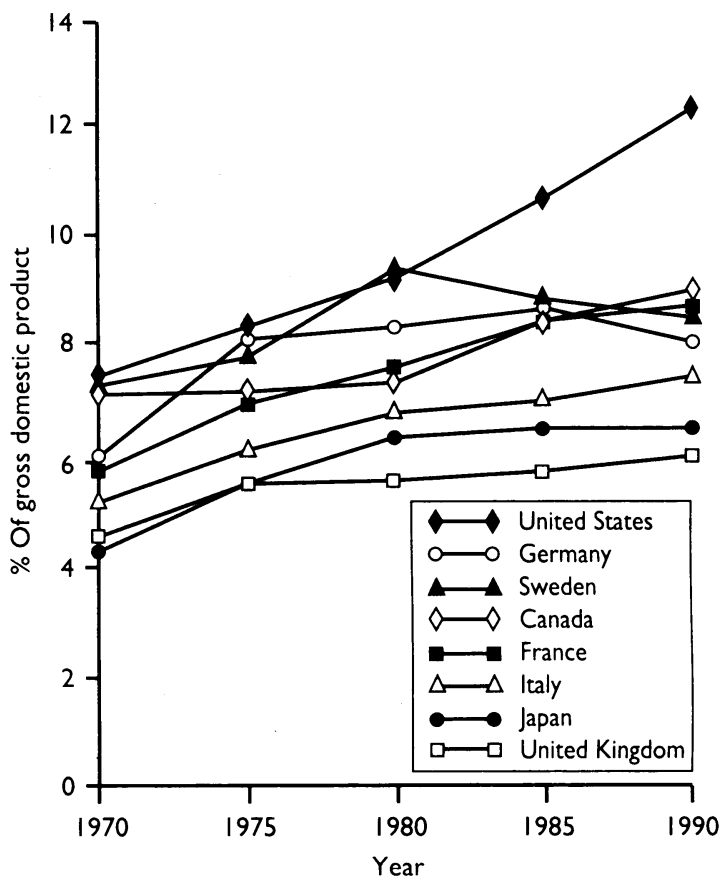

Total health expenditures of selected countries (members of OECD) 1970-90. (Source: OECD)

\section{Uninsured people}

Increasing costs mean that the 36 million Americans without health insurance face steeper out of pocket expenses for health services, yet they still manage to pay a significant contribution for the care they receive." Hospitals are the main providers of care for the uninsured, and care is paid for by patients directly through out of pocket payments, by state or local government through a public subsidy, or by the hospitals themselves. Hospitals have faced an increasing demand for care from the rising numbers of uninsured people, and a fast growing financial burden In 1988 they had to find $\$ 10 \cdot 7$ billion $^{11}$ to cover the cost of charity care (where the patient can't pay) and bad debts (where the patient or insurer won't pay). Private physicians are also faced with a growing bill for care of the uninsured.

\section{EFFORTS TO REDUCE COSTS}

Some hospitals have reacted by shifting the costs of the uninsured on to insurers by inflating the hospital bills of privately insured patients. For example, in New Jersey these bills have been increased by $30-60 \%$ in some inner city hospitals, while suburban hospitals (which serve few of the uninsured and more of the privately insured) have been able to keep surcharges as low as $4 \% .{ }^{12}$ Because there is less opportunity to "cost shift" in inner city hospitals, the financial burden of the uninsured is higher. ${ }^{13}$ To address this inequity most states levy a tax on the hospital bills of all patients. The 
proceeds of the tax are distributed to the hospitals providing the most care to uninsured people, but this still falls short of the total bill.

Hospitals have also reacted by reducing the services that uninsured people use the most-such as emergency room, obstetric, and outpatient services ${ }^{14}$ - and so have shifted costs on to other providers, Others are demanding a deposit from patients before any care is given. Once in hospital it is illegal to transfer an unstable patient to another hospital for economic reasons-a practice known as "dumping." However, stories of such transfers still reach the headlines ${ }^{15}$ and the laws on dumping still have to be fine tuned. Unlike hospitals, private physicians are not legally required to treat any patient who seeks care and are less willing to treat the uninsured as costs increase. Meanwhile, uninsured people are left to find care among a dwindling number of increasingly unwilling providers.

\section{Medicare and Medicaid}

In $1990,42.4 \%$ of national expenditure on health care was spent by federal, state, and local governments-two thirds of which went on Medicaid and Medicare. ${ }^{16}$ The Medicaid programme provides health benefits to 24 million poor and disabled Americans, while Medicare mainly provides benefits to 33 million elderly Americans (virtually all those over 65). In recent years growth in spending on both programmes has outstripped growth in the private sector: Medicaid spending rose by $20.6 \%$ in 1990 alone. ${ }^{16}$ Rising prices, rising use of services, and the rising number of Americans qualifying for Medicare and Medicaid have all contributed to the overall increase.

\section{EFFORTS TO REDUCE COSTS}

Since Medicare and Medicaid are publicly financed there is greater ability for federal government to contain costs in these programmes than in the private sector, where roughly 1800 insurance organisations pay for health services. Efforts to reduce costs have been directed by the Health Care Financing Administration-the national body which oversees Medicare and Medicaid-and have focused on curbing the prices and use of hospital care, the largest item in both the Medicaid and Medicare budgets.

In 1984, the Health Care Financing Administration introduced a new method of reimbursing hospitals for services to Medicare patients-the prospective payment system. Under this system hospitals are paid a fixed price for the care of each admitted patient, the price depending on the patient's diagnosis rather than the quantity of services the patient used. In this way hospitals are given an incentive to reduce the use of unnecessary inpatient hospital services. The prospective payment system also allows the Health Care Financing Administration to set national prices for services and control how fast they rise rather than leaving it up to each hospital. There is not a unique price for each diagnosis-instead, diagnoses are grouped with others which consume similar resources in hospital. Over 470 such diagnosis related groups have been defined, each assigned a price by the Health Care Financing Administration. The administration may also discourage the use of a new technology by assigning it to a lower priced diagnosis related group. ${ }^{17}$

A national fee schedule has been developed to set the rates physicians can charge for services to Medicare patients ${ }^{18}$ and was implemented in January 1992. The schedule is designed to reward physicians working in primary care and in underserved areas. There has been much resistance from organised medicine-particularly from higher paid specialists such as surgeons and cardiologists, who stand to lose income as a result. ${ }^{10}$

Federal government has encouraged the use of health maintenance organisations in Medicaid and Medicare. These organisations purchase and manage health care for the population enrolled with them. A health maintenance organisation receives an annual premium for each enrolled patient, and the premiums are pooled and used to buy care. If health maintenance organisations spend less than the total premium pool in one year they can keep the savings. Although there are many different types of health maintenance organisation, the incentives for each are to reduce unnecessary use of services by purchasing from efficient providers. Health maintenance organisations have been shown to cut costs of care significantly, mainly due to a reduction in hospital admissions. ${ }^{20}$

Utilisation review has been introduced into the Medicare and Medicaid programmes to check that on services used by patients are clinically necessary. This $\overrightarrow{0}$ work is carried out by independent peer review organisations, which can deny payment to providers $\vec{\omega}$ if care is deemed unnecessary. Denial rates are high for some procedures, such as hysterectomies $(21.5 \%$ denied), but average $11 \%$ across all outpatient and $\dot{\omega}$ inpatient services. ${ }^{21}$

The federal government provides a $\$ 67$ million $\infty$ annual budget to the Agency for Health Care Policy $\mathcal{O N}_{\infty}$ and Research to coordinate research into the effective- $\infty$ ness of medical treatments. ${ }^{22}$ Research activities in $\infty$ 1991 included studying the effectiveness of common 윽 procedures and new technologies, suggesting clinical $\vec{\nabla}$ guidelines, and examining the effects of cost containment initiatives. The results of this work are widely disseminated to influence care and payment rates in government programmes.

Cutting costs by reducing patient demand for care $\overrightarrow{0}$ has not been a major strategy pursued in either $N$ programme. Restricting numbers of individuals who can qualify or dropping coverage of specific health services in the Medicare programme would be politically difficult, given the strength of the elderly lobby. Within Medicaid federal laws have actually expanded the numbers enrolled, and only one state (Oregon) has proposed to curtail benefits, ${ }^{23}$ amid much controversy.

\section{EFFECTS}

Evidence suggests that the prospective payment system and utilisation review slowed the growth rate of total Medicare spending from 6.9\% per year between 1980 and 1984 to $4 \%$ per year between 1984 and 1987 흘 (after adjusting for general inflation, enrolment growth, and enrollee mix). ${ }^{24}$ Worries about hospitals skimping $ᄋ$ on quality of patient care to cut costs have not been $₹$ substantiated..$^{25}$ Enrolment in health maintenance $ᄋ$ organisations has grown, and over 5 million Medicaid $N$ and Medicare recipients have joined. Early results suggest that health maintenance organisations have been effective in reducing cost growth ${ }^{26}$ while patient satisfaction and the quality of care do not appear to be compromised.$^{27}$ But despite these efforts recent growth in hospital spending is approaching levels that existed before the prospective payment system. ${ }^{16}$ Also Medicare costs have ballooned in areas not subject to $\mathbb{E}$ cost containment efforts, such as outpatient care, physicians' services, ${ }^{28}$ and nursing home care. This has led to a search for a prospective payment system for outpatient care $^{29}$ and alternative methods of paying for nursing home care. ${ }^{30}$

\section{Privately insured people}

Three quarters of all Americans have some form of private health insurance, mostly obtained through the workplace. Premium costs jumped by more than $17 \%$ between 1989 and $1990^{31}$ and most of this rise has been absorbed by business rather than directly by employees. ${ }^{32} \mathrm{On}$ average business paid $\$ 3000$ for health 
care per employee in 1990, expenditure which represented a crippling $107: 9 \%$ of profits of American corporations after tax compared with $42.6 \%$ in $1980 .^{33}$ While the figures look bad for business, insurance companies are also in trouble. Despite raising premium charges top insurers are suffering significant underwriting losses for health insurance.

\section{EFFORTS TO CONTAIN COSTS}

Cost containment has been as eagerly pursued by businesses and insurance companies as by the Health Care Financing Administration. Most businesses now offer health maintenance organisation health plans to their workers, and employee enrolment in these organisations rose to $38 \%$ in 1990 -up by $27 \%$ since $1987 .{ }^{34}$ Utilisation management is a feature in the plans of $90 \%$ of all privately insured employees, ${ }^{35}$ and health maintenance organisations have been particularly active in their efforts to reduce inappropriate care. ${ }^{36}$ Unlike the Health Care Financing Administration, businesses and insurance companies have not fixed the prices payable to providers using a prospective payment system. Instead, they have relied on competition between providers to keep prices low.

But if businesses and insurance companies have tried to cut costs by encouraging providers and patients to behave more efficiently, they have also been creative in their tactics to shift costs elsewhere. To keep premium prices competitive insurers are charging businesses more for covering unhealthy workers ("bad risks") compared with the healthy ("good risks") and are refusing to insure workers with pre-existing costly illnesses. ${ }^{37} 38$ Some businesses have refused to hire employees who may be "poor risk" or require them to pay more for health insurance. Others have even tried to control the health habits of their workers by firing or fining those who are overweight or smokers. ${ }^{39}$ Still more have dropped coverage of workers' dependants, tried to limit health benefits offered, or stopped offering health insurance completely.

The effects of these cost containment measures have been limited. The rise in the cost of the average premium is now $14 \%$, although the rises in health maintenance organisation premiums have been roughly two thirds those of traditional health insurance plans. ${ }^{35}$ Meanwhile, Americans with private health insurance are faced with increased out of pocket expenses, an increasingly bureaucratic health system to negotiate, and a future where accessing health care will be more difficult.

\section{Conclusion}

The complex system of incentives existing in American health care has pushed spending inexorably upwards. As the cost balloon has been squeezed in one place it has expanded in another. Federal initiatives have attempted to contain costs in government programmes (mainly Medicare) with some success but have had less scope to act in the private sector. Meanwhile as businesses, the government, and the public have to pay more, the barriers to accessing care for uninsured people grow larger.

Next week we shall look at the reform proposals on offer, how the states are trying to solve the problems of cost and access, and the likely course of health care reform.
Much of this study was carried out in the United States in 1990-1 while I was in tenure of a Harkness fellowship.

1 Jencks SF, Scheiber GJ. Containing US health care costs: what bullet to bite? Health Care Financing Review 1991 ; annu suppl:1-12.

2 Organisation for Economic Cooperation and Development. Data held on computerised database. (OECD, Rue Pascal, 75001 Paris.)

3 Employee Benefit Research Institute. Sources of health insurance and characteristics of the uninsured. Analysis of March 1991 current population survey. Washington, DC; EBRI, 1992. (Issue brief No 123.)

4 Enthoven A, Kronick R. A consumer-choice health plan for the 1990s: universal health insurance in a system designed to promote quality and economy. N Engl f Med 1989;320:29-37.

5 Meyer J, Silow-Carroll S, Sullivan S. Critical choices: confronting the cost of American health care. Washington, DC: National Committee for Quality Health Care, 1990

6 Schroeder SA. Physician supply and the US medical marketplace. Health Aff 1992;11:235-43.

7 Pollack A. Medical technology 'arms race' adds billions to the nation's bills. New York Times 1991 April 29:A1

8 Blendon RJ, Edwards JN, Szalay US. The health insurance industry in the year 2001: one scenario. Health Aff 1991;10:170-7.

9 Woolhandler S, Himmelstein DU. The deteriorating administrative efficiency of the US health care system. $N$ Engl $f$ Med 1991;324:1253-8.

10 Wilensky GR, Berk ML. The poor, sick, uninsured, and the role of Medicaid In: Hospitals and the uninsured poor. New York: The United Hospital Fund of New York, 1985:33-47.

11 American Hospital Association. Direct financing of uncompensated care. Chicago: AHA, 1990.

12 Sullivan JF. When patients pay for charity to patients. New York Times 1991 March 22:B1, B2.

13 Feder J, Hadley J, Mullner RM. Falling through the cracks; poverty, insurance coverage, and hospitals' care to the poor, 1980 and 1982. In: Hospitals and the uninsured poor. New York: United Hospital Fund of New York, 1985:3-30.

14 Congressional Research Service. Health insurance and the uninsured. Washington, DC: Library of Congress, 1988

15 Lewin T. US law on hospital care of poor faces test. New York Times 1991 March 22:Al, A9.

16 Levit KR, Lazenby HC, Cowan CA, Letch SW. National health expenditures 1990. Health Care Financing Review 1991;13:29-54.

17 Kane NM, Manoukian PD. The effect of the Medicare prospective paymen system on the adoption of new technology. The case of cochlear implants. N Engl f Med 1989;321:1378-84.

18 Hsaio WC, Braun P, Yntma D, Becker ER. Estimating physicians' work for a resource-based relative value scale. $N$ Engl f Med 1988;319:835-41.

19 Glaser W'A. The politics of paying physicians. Health Aff 1989;8:129-46.

20 Luft HS. How do health-maintenance organizations achieve their "savings"? Rhetoric and evidence. N Engl f Med 1978;298:1336-43.

21 Bailit HL, Sennett C. Utilization management as a cost-containment strategy. Health Care Financing Revier: 1991 ; annu suppl:87-93.

22 Agency for Health Care Policy and Research. Medical treatment effectiveness research. Rockville, Maryland: Department of Health and Human Services, 1990.

23 Dixon J, Welch HG. Priority setting: lessons from Oregon. Lancet 1991;337 $891-4$.

24 Long $\mathrm{SH}$, Welch WP. Are we containing costs or pushing on a balloon? Health Aff 1988;7:113-7.

25 Coulam RF, Gaumer GL Medicare's prospective payment system: a critical appraisal. Health Care Financing Review 1991 ; annu suppl:45-77.

26 McCombs JS, Kasper JD, Riley GF. Do HMOs reduce health care costs? A multivariate analysis of two Medicare HMO demonstration projects. Health Serv Res 1990;25:593-613.

27 Wilensky GR, Rossiter LF. Co-ordinated care and public programs. Health Aff 1991;10:62-77.

28 Holahan J, Dor A, Zuckerman S. Has PPS increased Medicare expenditures on physicians? Health Polit Policy Law 1991:16:335-62.

29 Sulvetra MB. Achieving cost control in the hospital outpatient department. Health Care Financing Reviewv 1991; annu suppl 95-106.

30 Schenkler RE Comparison of Medicaid nursing home payment systems. Health Care Financing Review 1991;13:93-109.

31 Freudenheim M. Health care a growing burden. New York Times 1991 Jan 29: $\mathrm{D} 1, \mathrm{D} 9$.

32 Gabel J, DiCarlo S, Sullivan C, Rice T. Employer sponsored health insurance, 1989. Health Aff 1990;9:161-75.

33 Inglehart $\mathrm{JK}$. The American health care system. Private insurance. N Engl f Med 1992;326:1715-20.

34 Hoy EW, Curtis RE, Rice T. Growth and change in managed care. Health Aff $1991: 10: 18-36$

35 Sullivan CB, Rice T. The health insurance picture in 1990. Health Aff 1991;10:104-15

36 Faltermayer E. Let's really cure the health system. Fortune 1992 March 23: $46-58$.

37 Kramon G. Medical insurers vary fees to aid healthier people. New York Times 1991 March 23:A1.

38 Cotton P. Pre-existing conditions 'hold Americans hostage' to employers and $T$ insurance. JAMA 1991;265:2451-3.

39 Sipress A. Cigarettes, other habits, can cost someone a job. Washington Post 1991 April 30.

(Accepted 13 August 1992) 